\title{
O ESTUDO DA TERRA COMO LAR DAS PESSOAS
}

\author{
Christian Dennys Monteiro de Oliveira* \\ Tiago Vieira Cavalcante**
}

\section{RESUMO:}

O estudo da Terra constitui o desafio maior para a compreensão do pensamento Geográfico. Tratase de uma perspectiva que percorre diferentes escolas nacionais e metodologias sistematizadas, sobretudo nestes últimos 150 anos de reflexão técnico científica. Entretanto dois fundamentos do processo foram negligenciados para a maioria dos geógrafos: a) a correta articulação de escalas de importância e abordagem para atender os valores humanos; b) o sentido significativo do próprio estudo enquanto criação de um espaço-destino. Este trabalho recupera a caracterização da Terra, pela Geografia Humanística, como a representação de um "lar"; um espaço de convívio capaz de sintonizar valores, sentimentos e mudanças na comtemporaneidade. O texto apresenta, em referência aos estudos de Eric Dardel e Jean-Marc Besse, uma sugestão de enfrentamento conceitual para ser desenvolvido em futuras pesquisas: Trabalhar a ideia de "lar em trânsito", incorporando a efemeridade e as mobilidades contemporâneas.

PALAVRAS-CHAVE:

Lar; Geografia humanística; Cultura; Escala; Espaço vivido.

\section{ABSTRACT:}

The study of the Earth is the biggest challenge to understanding the Geographic thought. It is a prospect that passes through different national schools and systematized methodologies, especially the past 150 years of technical scientific thought. Meanwhile two fundaments of the process have been neglected for most geographers: a) the correct articulation of importance scales and the approach to get human values b) the significative meaning of the study itself as a creation of a space-destination. This work recovers the characterization of the Earth, by Humanistic Geography, as the representation as "home", an area of coexistence able to tune values, feelings and changes in the contemporary period. The text presents, in reference to studies by Eric Dardel and Jean-Marc Besse, a suggestion of conceptual confrontation to be developed in future researches: Working the idea of "transit home", incorporating the ephemeral condition and the contemporary mobility. KEY WORDS:

Home; Humanistic geography; Culture; Scale; Lived space.

\footnotetext{
* Professor adjunto do Departamento de Geografia da UFC. Doutor em Geografia Humana pela FFLCH/USP e Pós-Doutor em Turismo pela ECA/USP. Pesquisador de Laboratório de Estudos Geoeducacionais do Núcleo de Avaliação de Políticas Públicas - NUMAPP/UFC. E-mail: cdennys@ufc.br **Bacharel em Turismo pela UNIFOR, especialista em Turismo pelo CEFFET-CE e Graduando em Geografia e Bolsista de Monitoria no curso de Licenciatura da UFC. E-Mail: tiagogeografia@yahoo.com.br
} 


\section{Considerações Iniciais - Uma Breve História da Reificação na Geografia}

“As pequenas coisas parecem nada ser, mas elas nos dão a paz.

São como as flores do campo;

a gente pensa que nenhuma tem perfume, mas todas juntas perfumam o ar".

Gandhi

É interessante perceber no mundo os diferentes olhares que as pessoas têm para com ele. Sujeitos do/no espaço, estas pessoas tendem, mesmo diante de altruismos, perspectivas morais, métodos etc., a tomarem o mundo como seu, no sentido de possuirem um olhar pessoal, peculiar sobre o planeta. Os cientistas, nesse contexto, têm grande destaque. Com o olhar que possuem do mundo, superficializam o contexto íntimo do outrem e constroem modos generelizadores e, acima de tudo, pessoais de explicá-lo.

Em grande parte da história da racionalização e cientifização na/da Geografia tal fato não tem acontecido de modo diferente. Contextualizando de forma breve, inicialmente temos o positivismo Comteano como base metodológica. Metanarrativa empírica que dá ênfase ao objeto em detrimento da importância das representações do sujeito para com este. A natureza é reificada.

Outras correntes também se estabelecem, apesar do pouco destaque inicial; é o caso da Geografia Cultural com bases em Sauer da escola de Berkeley. Porém, esta do mesmo modo, descreve elementos culturais principalmente relacionados ao gênero de vida nas paisagens rurais onde, por exemplo, a complexidade e urbanidade das emergentes cidades não fazem parte da realidade. 0 empirismo e o historicismo também se estabelecem, assim como a cultura é reificada, haja vista grande influência da Antropologia de Kroeber e White.
A corrente Teorético-quantitiva, também denominada de Nova Geografia vem a posteriori buscando ainda tratar do caráter científico da Geografia, quantificando seus preceitos, ou seja, fazendo uso de recursos, em especial, da Matemática e da Estatística nas suas análises espaciais. Porém, apesar de tal base em muito ter contribuído, por exemplo, para o desenvolvimento da Geografia Física, suas considerações quanto aos agentes sociais, assim como para com as contradições, o tempo e as transformações são inexistentes ou relegadas a um plano secundário (CORRÊA, 2005). Nesse sentido, as angustias e necessidades dos indivíduos não constam nos altos geográficos de órgãos como o Instituto Brasileiro de Geografia e Estatística - IBGE. Reifica-se o dado.

A Geografia Nova, tomando como base título do livro de Santos (1978); Por uma Geografia Nova, é tomada como crítica aos preceitos positivistas e neopositivistas por estes não levarem o constructo da sociedade em consideração. Para estes o espaço é o locus da reprodução das relações sociais de produção (CORRÊA, I dem). Com bases na filosofia marxista, constroem seus preceitos e teorias com o propósito de abarcar o todo social, a sociedade, desse modo elaborando metanarrativas que levam em consideração o todo em detrimento do específico, a sociedade em detrimento do indivíduo. Tendo assim, uma supervalorização do homo economicus, do homo faber, reifica-se a economia.

As reificações dentro da ciência tem sido uma práxis. Em busca de estabelecer métodos a ciência separa sujeito e objeto com base nas filosofias de Descartes e na cientificidade de Galileu e Newton, assim como também toma grande distância da Arte e da subjetividade inerente ao ser humano. De todo modo na Geografia - assim como, acreditamos, também nas outras ciências tal perspectiva tem trazido prejuízos epistemológicos e, especialmente, ontológicos. 
A dificuldade de contato com as outras ciências (disciplinas) - interdisciplinaridade - , assim como a deficiente possibilidade de contato entre os diversos métodos geográficos intradisciplinaridade - são exemplos desse prejuízo denunciado por Hissa (2002) que afirma: "Todos os "homens de ciência" deveriam ser filósofos: não seriam intrusos, estariam exercitando o necessário movimento de conjunção de saberes" ( p. 223, 224). Eis o prejuízo epistemológico.

Outro fator também deve ser considerado. No contexto das metanarrativas científicas, as pequenas coisas - de representação espacial menor ou efêmera - parecem nada conter de significativo. Embora em termos individuais, muito do que consideramos por "paz", conforme Gandhi, tem nessas o único porto seguro. Tomando a Terra como campo de estudo, o geógrafo tende a fazer generalizações muitas vezes incapazes de lidar com esse campo espacial diminuto. Tendência esta que não considera a natureza da complexidade dos diversos elementos do planeta, sejam estes naturais ou sociais. Na Geografia percebe-se a referência à conceitos como espaço e região (em pequena escala) em detrimento dos territórios (em grande escala) e dos lugares, espaços vividos. Eis o prejuízo ontológico.

A partir de tal contextualização, esse ensaio pretende-se esclarecedor no que tange as dificuldades que a ciência geográfica tem perpassado. Desse modo tem-se como intuito, de início, fazer uma breve discussão sobre a questão das escalas em Geografia para posteriormente com base nos preceitos da Geografia Cultural-Humanística - tendo escolhido a devida escala - possamos fazer uma discussão da Terra como lar das pessoas.

\section{Humano \\ Às Escalas do Ser e do Estar: 0}

“Não é a distância que mede o afastamento. O muro de um jardim de nossa casa pode encerrar mais segredos que a muralha da China, e a alma de uma simples mocinha é melhor protegida pelo silêncio

do que os óasis do Saara pela extensão das areias".

Antoine de Saint Exupéry

Se a discussão aqui delineada diz respeito à complexidade daquilo que pode ser apreendido pela Geografia e como deve ser realizada tal apreensão, não partindo nem para a elaboração de metanarrativas nem de reificações, vale destacarmos logo de início que é à escala do indivíduo/grupo - do ser humano - que pretendemos chegar. Partimos do pressuposto que essa escala apreende de melhor maneira as angústias e necessidades do ser, fazendo com que a partir de sua consciência do espaço possamos entender a relação destes grupos indivíduais e coletivos, em suas diversas condições existenciais, para com a Terra. Na Geografia, tal consideração corresponde a uma percepção escalar; o que exige uma breve discussão sobre este conceito.

Castro (2005, p. 118) de início indica dois problemas vinculados à escala: o problema dimensional, "que inclui (...) a inseparabilidade entre tamanho e fenômeno, como a complexidade dos fenômenos e, a impossibilidade de apreendê-los diretamente", característica de um problema também fenomenal. Nesse sentido, deixa claro que a escala, “é, na realidade, a medida que confere visibilidade ao fenômeno. Ela não define, portanto, o nível de análise, nem pode ser confundida com ele, estas são noções independentes, conceitual e empiricamente" (Idem, p. 123). Sendo assim, os geográfos ao abordarem os fenômenos espaciais, antes de mais nada, tem de ter plena consciência que ante a complexidade dos fatos geográficos a escala abordada é apenas fragmento da realidade. Castro esclarece afirmando: "o que é visível no fenômeno e que possibilita sua mensuração, análise e explicação depende da escala de observação" (I bidem, p. 131). 
Diferentes escalas trarão/darão diferentes resultados sobre uma observação, o que significa que o embate entre as grandes escalas (que abarcam os microespaços) e as pequenas escalas (que analisam os macroespaços), é parte da realidade da Geografia, haja vista também o problema que se tem na transferência de situações de uma escala à outra. Castro (op. cit) neste mesmo contexto, nos ajuda, afirmando:

(...) a informação factual, os dados individuais ou desagregados, os fenômenos manifestos, a tendência à heterogeneidade, a valorização do vivido são atributos dos fenômenos observados em grande escala, enquanto a informação estruturante, os dados agregados, os fenômenos latentes, a tendência a homogeneização e valorização do organizado são atributos dos fenômenos observados na pequena escala. Homogeneidade e heterogeneidade resultam da pespectiva de observação, fruto de uma escolha, que deve ser consciente e explicitada (p. 126, 127).

Vale ressaltar que deve haver consciência por parte do geógrafo da interrelação entre elementos apreendidos por grandes e pequenas escalas, visto que,

A escala é também necessariamente uma medida, mas não necessariamente do fenômeno, mas aquela escolhida para melhor observá-lo, dimensioná-lo e mensurá-lo. Não é possível, portanto, confundir a escala, medida arbitrária, com a dimensão do que é observado (I dem, I bidem, p. 127).

Na mesma perspectiva, podemos tomar como exemplo, a necessária relação que deve ser efetuada entre o(s) lugar(es) e o mundo, na tentativa de constituir uma contextualização geográfica dos fenômenos socioculturais, políticos e econômicos. Sem, contudo, comprometer o espaços das intersubjetividades, que ampliam as contingências do próprio estar no mundo por intermédio dos lugares. Daí a aposta, rigorosa e ousada, em uma abordagem que permita pensar escalas de hierarquia invertida: o mundo, como generalização, constitui-se menor do que os lugares, dada a força de significação destes últimos. Em termos mais filosóficos: o ser humano pode (e deve) geograficamente subordinar-se ao estar humano. Nao só para "fugirmos" dos idealismos mais nobres que alimentaram os fundamentalismos mais perversos; mas para lembrarmos que a vivência contemporânea das pessoas permanece aprisionada por uma rotina de grande escala (micro extensão) e frágil comunicação com os grandes questões geográficas contemporâneos. Talvez por essa razão, ainda pouco avaliada epistemologicamente, a Geografia mantenha-se como um pensamento crítico-descritivo distanciado da criatividade. A criatividade da sobrevivência cotidiana.

É na busca dos elementos que a grande escala apresenta que entendemos ser melhor trabalhar, visto a potencialidade de melhor compreensão do espaço a partir das peculiaridades que ele apresenta, como os fenômenos manifestos, a consciência da heterogeneidade, a valorização do vivido e de seu espaço - espaço vivido nas palavras de Eric Dardel (1990). Vale lembrar que a dialógica grande/pequena escala e sujeito/objeto na busca de uma intersubjetividade tem que ser idealizada para a compreenssão mais abrangente do recorte estudado. É a consciência e sensibilização ante a complexidade do que é objetivo e subjetivo da/na interpretação geográfica.

\section{A Geografia Cultural-Humanística}

“O geógrafo habita o mundo ao mesmo tempo que procura compreender-Ihe as estruturas e os movimentos".

Jean-Marc Besse

Dentro das possibilidades de se geografar ${ }^{1}$, ou seja, de fazer Geografia buscando a compreensão do planeta, levandose em consideração os objetos da Geografia, 
mas também seus sujeitos e a consciência destes para com tais objetos, busca-se efetuar tal interpretação, compreensão, a partir de uma Abordagem Cultural da Geografia delineada e contemplada, por exemplo, por Claval (2002, 2003), que nas palavras de Marandola J r. (2005) aproxima a perspectica cultural clássica da postura Humanista em Geografia. Tal aproximação se dá pela ligação que ambas têm com a raiz filosófica fenomenológica existencialista, "como crítica ao objetivismo científico" (MARANDOLA J R., 2005, p. 409). Nesse sentido, ambas dão enfoque a experiência humana, renunciando aos pontos de vista totalizadores e as generalizações. Partem do indivíduo e de suas experiências temporoespaciais, pois é através delas que estes relacionam-se com o mundo em seu âmbito social, cultural, político e econômico. De acordo com Marandola Jr (I dem, p. 410),

(...) o elo que une a Abordagem Cultural e o Humanismo em Geografia: não é apenas devido à subjetividade humana, tampouco devido somente à cultura. A resposta está exatamente no encontro destas duas dimensões, que possuem uma diferença escalar que se cruza em dois pontos: no micro (o indivíduo) e no macro (a coletividade). É por isso que o Humanismo em Geografia não pode reduzir-se a Geografia Humanista: esta centra sua abordagem no indivíduo e seus temas de estudo estão claramente identificados com a investigação da experiência humana através desta escala. (...) Similarmente, a Geografia Cultural possui como meta explorar a vivência e experiência humana na escala social, dos grupos e de seus mebros. Seus temas de pesquisa apontam para esta orientação. (...) Estudar como as pessoas vivem seus espaços existenciais sem considerar a cultura em que estão imersos, é uma tarefa tão difícil quanto estudar a coletividade sem considerar a dinâmica dos indivíduos.

É este o motivo que nos leva a acolher tal postura que justifica de modo pleno a ligação entre duas correntes de tempos históricos distintos, porém de finalidades similares. É um motivo de cunho escalar e consciente da complexidade dos significantes e signicados do mundo. Eis o porque do subtítulo presente ter sido denominado: A Geografia CulturalHumanística.

A postura crítica para com a tradição positivista e o ideário racionalista e totalizante de se compreender os significantes e significados do mundo, embasa-nos quando sabemos que a pretensão é de se trabalhar em um contexto científico transdisciplinar e transescalar. A escala do ser, do indivíduo, nessse contexto, serve-nos de premissa metodológica, haja vista a possibilidade de a partir dela podermos abordar, pelo menos com maior embasamento humano, os questionamentos gerais que nos exigem as metanarrativas. Metanarrativas estas que, digase de passagem, quando provenientes de correntes como a da Geografia Radical, de base marxista, não se desvencilham do Humanismo, porém possuindo um contexto escalar diferenciado, voltam-se principalmente à pequena escala.

Contudo, o que nos revela tal abordagem? Ao nosso ver, ante a complexidade do mundo, tal abordagem permite principalmente aproximações. Esta é a palavra chave. Há muito se tem feito críticas a ciência que tem pés fincados no renascentismo moderno. Tal crítica ao mesmo tempo que realizada, fomenta novas posturas, ou pelo menos, a redefinição de posturas há muito desvencilhadas, separadas principalmente pela base filosófica racionalista cartesiana. É nesse sentido que trabalhos como a obra de título: A Mobilidade das Fronteiras: I nserções da Geografia na Crise da Modernidade, de Cássio Eduardo Viana Hissa (2002), nos ajudam a perceber que ante a crise da modernidade, tem-se necessitado por parte da ciência e mais especificamente da ciência geográfica, uma maior aproximação com outras disciplinas (transdisciplinaridade), com o sujeitos que fazem partem do mundo e o concebem intersubjetivamente e finalmente com a Arte. Atitudes talvez capazes de aproximar a ciência 
do indivíduo e, principalmente, de seus anseios, angústias e necessidades humanas, para além somente das econômicas. Nesse sentido, temos a Terra como bem das pessoas e não tão somente como recurso passível de ser usado para fins sócio-econômicos (des)humanos. Para finalizar explicitamos com Besse (2006, p. 82, 83):

(...) a Geografia deve ser considerada como fundamental para toda questão sobre a modernidade. E isto não somente por ela acolher e permitir o aprofundamento das indagações "positivas" concernentes às formas modernas de espacialidade, mas porque esta disciplina é exemplar do parcelameto das relações que mantemos hoje em dia com o mundo terrestre.

Assim, não é tanto a Geografia como um saber positivo (inclusive nos problemas veiculados por esta própria positividade) que se deve considerar aqui, mas antes a Geografia na medida em que ela se encarrega das relações que nós mantemos com o mundo terrestre, e na medida em que ela é uma indagação, sobre as diferentes maneiras possíveis de falar deste mundo.

\section{Lares, Doce Lar em Movimento}

“Lar é a palavra unificadora para todas as principais subdivisões da Geografia, seja na escala familiar da casa ou do planeta".

\section{Yi-Fu Tuan}

Um dos grande desafios para a abordagem cultural e humanística reestruturar o conhecimento geográfico está na identificação das refências espaço-temporais. A escala do ser na contextualização cotidiana requer transitórias e multifacetadas "escalas do estar". Eis a abertura para a complexidade teórica que impede o enquadramento direto da Geografia Humanística nas estruturas idealistas de análise. Não há uma única e ideal constituição do homem-espécie como subjetividade (significativa e significante); há múltiplas constituições; especialmente quando nos reportamos ao contexto da vida constemporânea, poluida e amarrada por tantos e todos os valores urbano-industriais. Uma vida capaz de multiplicar infinitamente os desejos tecnológicos, as dependências institucionais e a necessidade de imagens.

É no interior desse espectro que o pensamento de Yi-Fu Tuan sobre a geograficidade do lar, pode ser enriquecida na mobilidade de sua interpretação. Em princípio, nenhum lugar comunica mais sentido ao ser humano do que o espelhamento das condições essenciais e estéticas de seu lar. Coletivamente, pode-se extender a mesma concepção, amparando-a em pressupostos ideológicos capazes de sistematizar identidades locaisregionais-nacionais reconstituidas. Sempre atendendo a conformidade com a escala de interesses políticos priorizados.

Contudo, o "Lar Doce Lar" é como o "Reino dos Ceús" cristão ou a "Terra sem Males" guarani. Guardadas as devidas especificidades, são lares como meta de um grande projeto existencial, recolocado cotidianamente, como a etapa-alvo de uma grande caminhada. É nesse caminho que os lares provisórios - do trabalho, do estudo, dos lazeres, das lutas sociais, do trânsito e das instituições - desenham o movimento e o papel da pluraridades de formas de estar na Terra. Uma plurarilade que não se esgota na compreensão da constituição natural desse Lar, como pressupõe boa parte da Geografia Física; nem é essencialmente atingida pelas formulações sócio-culturais constituintes do discurso central da Geografia Humana. Em uma Geografia Humanística, capaz de operar na densidade pluralista dos lares transitórios (que a Terra tende a representar) constituimos um estudo geográfico incorporador das intencionalidades. Um estudo forjado pela interpretação das relações humanas e naturais, como manifestação de interpretações; e não como indicadores isolados de objetos ou sujeitos em ação/reação. Trata-se de uma mudança epistêmica fundamental; gestora de um exercício metodológico instigante: Interpretar a relação homem-natureza, em 
todas as suas variações para descrever, em profundidade, como as manifestações dessa mesma relação se interpretam; se mobilizam na experiência telúrica do lar.

Voltamos a leitura de Yi-Fu Tuan para reconstituir sua ideia de "conscientização" como estratégia de afloramento desse universo plural de significados. Distanciando-se da crítica predominantemente psicológica, que alerta para a consciência como um pressuposto existencial do ser humano saudável, sua abordagem prepara o caminho de uma leitura metodológicamente interpretativa da consciência. Como um dos precursores da Geografia Humanística, ao lado de nomes como Relph e Buttimer, Yi-Fu Tuan (1985, p. 146) afirma que:

As abordagens científicas para o estudo do homem tendem a minimizar o papel da conscientização e do conhecimento humano. A Geografia Humanística, em contraste, tenta especificamente entender como as atividades e os fenômenos geográficos revelam a qualidade da conscientização humana.

Certamente que a conscientização humana o qual Tuan se refere, diz respeito a qualidade humana subjetiva de se relacionar com os objetos pertencentes ao espaço geográfico. Tal consciência é diversa e estabelece modos relacionais do sujeito para com objeto, com base em afinidades, desejos, sentidos, significados etc, ou seja, através dos sentimentos inerentes ao ser-humano. Lowenthal (1985), em artigo pioneiro no que cerne à consciência do indivíduo para com o espaço, indica a relação entre o mundo exterior e as imagens nas cabeças das pessoas, imagens percebidas de modo diverso, sendo esta visão das imagens ricamente diferenciada. O autor leva em consideração na compreensão da diferença de tais percepções do mundo as mais diversas variáveis. Para Lowenthal (Idem, p. 141): “Cada imagem e idéia sobre o mundo é composta, então, de experiência pessoal, aprendizado, imaginação e memória". I magens estas apreendidas a partir praticamente de todos os sentidos humanos.
Porém, podemos nos perguntar diante das afirmações até aquí estabelecidas: Dentro de um ambiente planetário onde a escala do ser é relevante para a compreensão do todo, tendo consciência da relação subjetiva, mas também objetiva que estes entes têm com o material e imaterial no planeta Terra, como orientar uma prática sensibilizadora para a concientização do indivíduo e por conseguinte da sociedade para com as problemáticas que suas atitudes (ir)racionais e (des)humanas têm trazido?

Ruy Moreira (2007) nos dar pistas do problemas o qual temos que enfrentar, em seu texto de viés ontológico: O Mal-Estar Social no Fim do Século $X X$, do livro Pensar e Ser em Geografia: Ensaios de História, Epistemologia e Ontologia do Espaço Geográfico. Nele Moreira indica a separação homem/espaço, afirmando que dele (do espaço) o homem foi organicamente apartado. Para Moreira (Idem, p, 133),

(...) O final do século XX também tem seu malestar geográfico, um mal-estar determinado pelo modo de ser-estar-espacial criado como cultura no Ocidente, onde o homem está, mas não é espaço. Tal mal-estar é uma mistura de desenraizamento e manipulação do imaginário que hoje se põem em evidência na formas das guerras de destruição, violência generalizada e perdas de referência humana.

No nosso entender a separação homem ó espaço tem vínculo direto com a idéia de racionalidade, portanto de origem na Antiguidade e, como delinea Moreira (I dem), tendo na contemporaneidade premissas fortemente econômicas. É o início do entendimento do porque do ser humano ter tido só mais recentemente noção da amplitude do mal-estar ontológico de tal separação. A desnaturização (separação homem/natureza), seguida da desterreação (separação homem/ terra) e da desterritorialização (separação homem/território) tem para Moreira (Ibidem) a desespacialização do homem que toma o espaço como um dado abstrato. O homem desse 
modo não se reconhece no espaço. Vale ressaltar que o ideário contruído por Ruy Moreira para essa desespacialização do indívíduo tem embasamento marxista. Não por isso certamente há de ser desconsiderado, haja vista que é exatamente o que não estamos fazendo no presente ensaio. Porém, vale perguntar: Será que tal ideário pode abarcar a desespacialização de toda a humanidade? Aceditamos que não.

O contexto que Moreira constrói, desse modo tem bases, na premissa marxista da acumulação primitiva do capital, quando do homem é retirada a terra e o direito de viver nela/dela, tendo assim que se deslocar (migrar) para os grandes centros, desse modo, juntando-se a montante dos indivíduos mão-de-obra de reserva de trabalho. Seu ideário é somente um olhar ideológico, uma das faces do problema que, sim, nos ajuda a perceber a atitude que grande parte dos indivíduos que têm hoje o planeta como uma grande dispensa de recursos de valor. De todo modo, a partir de tal ideário os seres humanos, mesmo assim, não podem efetivar ligação afetiva com os lugares? Tenhamos cuidado com truísmos ideológicos que por vezes podem nos atrapalhar. Simplificar a percepção e interpretação dos fatos. "Em vez de lamentar o advento da sociedade móvel e condená-la como patológica e exploradora necessária da natureza, poderse-ia imaginá-la como um desafio para desenvolver um novo respeito pelo espaço, tempo e natureza" (BUTTIMER, 1985, p. 66).

Corroboramos com Buttimer, acreditando também na desespacialização por falta de conscientização e, em especial, sensibilização dos indivíduos para com o seu lugar. Talvez um princípio educacional. Lugar este tomado como lar nas palavras de Tuan que segundo Mello (2001, p. 91):

Trata-se, seguindo os princípios fenomenológicos referentes à noção do mundo vivido, de um centro pleno de valores e aspectos familiares indissociavéis, assim como de evocações que permitem a pessoa "sentir-se em casa.

Hissa (2002) clarifica dizendo que, ainda vivemos em um mundo tomado por atos racionais. A consciência de uma relação entre a ciência e arte já há um bom tempo tem feito parte das discussões acadêmicas, porém tais discussões ainda não permeiam o ideário dos leigos, assim como, não têm ganho espaço nas próprias universidades e na teoria científica, principalmente, das ciências ditas "duras".

Na Geografia ainda faz-se mais trabalhos geométricos do que trabalhos propriamente geográficos, nos termos de Dardel (1990, p. 02) ao considerar que,

La géométrie opère sur un espace abstrait, vide de tout contenu, disponible pour toutes les combinaisons. L'espace géographique a un horizont, un modelé, de la couleur, de la densité. Il est solide, liquide ou aérien, large ou étroit: il limite et il résiste. ${ }^{2}$

Fato este (a geometrização do espaço) que corrobora, acreditamos, com uma visão geográfica míope e minimalista, portanto simplista, por parte de grande parte dos profissionais de Geografia.

Dentro de um contexto mais amplo é possível perceber ainda parte da teoria científica desprezando os fatos cotidianos, em especial, aqueles mais peculiares. O método científico teimosamente resiste à voz subjetiva proveniente do ser, às diferentes formas de arte como maneiras também de 'desvestir' o mundo. $\mathrm{Na}$ cidade contemporânea - símbolo do ideário moderno -, o discurso institucionalizado muitas vezes não dá ouvidos à voz do povo, deste modo construíndo espaços em princípio vazios, que por felicidade, com o tempo (de forma inconstante) são tomados (apropriados) pela população. Mesmo tendo que considerar, o fato de tais espaços serem reconhecidos por diferentes grupos de indívíduos que estabelecem alí território. Território este flexível e passível de ser desisntitucionalizado 
simbolicamente. O território, de todo modo, é um conceito que como diz Souza (2005) necessita de dois elementos: espaço e poder. Vinculados a questão do poder tal conceito (território) tem caráter mais político do que propriamente afetivo, apesar de identitário.

O lugar, como indica Corrêa (2005), é o conceito chave dentro de um contexto culturalhumanístico. Viabiliza, nesse sentido, melhor compreensão por parte do geógrafo, da relação do ser humano com o seu lugar, o seu lar. Para além de uma Geometria do espaço talhado em detrimento do contexto emocional a ele vinculado, a Geografia tem que se ater a geograficidade, visto que tal conceito, vinculado à obra de Dardel (1990),

(...) refere-se á cumplicidade obrigatória entre a Terra e o homem, que se apresenta à existência humana. Refere-se também a um espaço material, uma matéria que não podemos descartar. A especialização da matéria exige do homem um comportamento ativo, no qual a "distância" é um elemento essencial na estruturação do mundo e não é experimentada espacialmente como quantidade, mas como qualidade expressa no "perto" e no "longe", no "lá" e no "aqui" (HOLZER, 2001, p. 111).

$\mathrm{Na}$ contemporaneidade uma certa nostalgia para com a natureza aponta para uma nova busca de conscientização do espaço. Seja este concebido pelo homem, seja este o espaço primitivo, porque natural. Porém, como o próprio Moreira (2007) coloca, o homem ainda não se vê com raizes fincadas no espaço. "Vê-se espacializado, mas não se compreende como espaço. Sente uma sensação de falta. Um vazio de pertencimento" (p. 141). Tal fato se dá como consequência da supra-organicidade do homo economicus? Ou talvez por institucionalizações filosóficas e científicas que ao enxergarem o homem apartado da natureza, desenraizaram-no? Ambas os questionamentos procedem, são relevantes. Como magistralmente coloca Buttimer (1985, p. 191),
A percepção tardia revela como grande parte das relações do homem com a natureza é uma função da maneira acadêmica que as mentes construiram da vida, do valor, da riqueza e da racionalidade. Para sanar as áreas degradadas e para erodir os anacronismos e injustiças em nossa maneira atual de racionalização do espaço, demanda-se mais que campanhas contra a pobreza, fome ou guerra internacionais; uma reorientação radical do pensamento e da visão dentro da Geografia também é requerida.

O lar, nesse sentido, nasce como possibilidade para além do contexto, da casa, da rua, da praça. Tuan (apud Holzer, 2001) ao explicar sobre o conceito de lar, o contextualiza nas mais diversas escalas; da velha casa à pátria. I mportando principalmente "(...) os laços que unem os homens a "seus" nichos de proteção e convivência ou concepção simbólica" (p. 91). Podemos assim, diminuir estas escalas e levá-las a possibilidade de apreensão por parte dos indivíduos de todo o planeta Terra? A resposta é positiva, pois, "habitar a Terra não é aninhar-se num Lugar, mas habitar um espaço que se abre entre um aqui e um ali, é percorrer este espaço em todos os sentidos" (BESSE, 2001, p. 93).

Pensamos, e é o que temos tendado explicitar no decorrer desse trabalho, que uma a Abordagem Cultural da Geografia em conjunção com uma postura Humanista também em Geografia, tem condições, ao reconhecer a complexidade dos fatos - sejam estes culturais, sociais, políticos, econômicos, objetivos, subjetivos, materiais, imateriais, simbólicos, ideológicos etc - , de fomentar um imaginário da Terra como lar das pessoas (lar em trânsito, como veremos a seguir). I maginário também capaz de atingir os preceitos científicos, fazendo com que estes possam estabelecer aproximação com a intersubjetividade inerente à possibilidade humana de criar, imaginar, sonhar e viver. Afinal, o cientista geógrafo (assim como tantas formas dos homens comuns) é um estar humano, apesar de por vezes fazer questão de tratar os humanos com meros objetos de sua pesquisa. Talvez porque não visualizem em seus, 
laboratórios, academias, escolas, institutos, etc. a diâmica transitória de um lar. Mas tão somente a perenidade de um templo. Um lugar sagrado no qual pela "ausência científica" de deuses, só Ihe resta vestir essa função. Eis o perigo de sempre, para todas as Geografias.

\section{(Re)Considerações Finais ( Re) Aberturas}

\author{
"Mas terei sido infiel ao meu fim \\ se vos levei em primeiro lugar a adimirar os \\ homens. \\ O que antes de tudo é admirável \\ é o terreno em que eles se desenvolveram". \\ Antoine de Saint-Exupéry
}

Se a dimensão humanística-cultural pode conjugar-se com os campos de investigação geográfica criando novos sentidos; e se o enquadramento representado por essa conjugação não sugere apenas uma espécie de minimalismo interpretativo - como se o desafio fosse produzir uma geografia dos sentimentos e emoções humanas - é possível sugerir que a idéia de "lar" se constitua conceitualmente. Ao fazê-lo, o relevante é a premissa de compreensão da consciência humana intersubjetiva, que aponta, na busca do espaço terrestre (o espaço-morada), algo mais aquém do que sua natureza física e (ao mesmo tempo) mais além do que as fantasias capitalistas ali representadas.

Interessa-nos, particularmente, a representação desse lar morada em dois planos correlatos ao campo vigente das crenças (sincretismo cristão ocidental), que transfere da racionalidade moderna à religiosidade pós-moderna - mídiática, turística e espetacular - o sentido das representações sociais contemporâneas. Daí ser possivel a composíção de estudos em Geografia Cultural-Humanística cujo foco de investigação absorva os seguintes desafios:
1. Na Geografia Escolar - Que tipo de lar a escolaridade mais elevada da última geração contruiu, manteve ou destruiu diante das gerações que confiaram seu filhos a essa escolarização?;

2. Na Geografia do Turismo e / ou Rural - Até que ponto as segundas residências de locais turísticos representam o habitar mais significativo das sociedades urbanas, independentemente de sua condição de renda?

3. Na Geografia Econômica e Urbana Como interpretar a informalidade, a pirataria e a cadeia social de explorações nas periferias, ignorando que as comunidades locais tranformam em lares privatizados, os espaços públicos?

4. Na Geografia Política Internacional Por que os campos de refugiados são estruturados e ampliados na mesma lógica fronteriça dos condomínios de elite das grandes cidades industriais?

5. Na Geografia Ambiental - Como evitar ocupar áreas de riscos e anecúmenos se o significado do enfrentamento coletivo da vida e da morte só se justificam plenamente nesses lugares?

6. Na Cartografia - A gestão de sinalização dos lugares e regiões demanda mais códigos padronizados ou as entrelinhas da desinformação, como um simbolismo que precisamos estar perdidos para termos que nos encontrar?

Pode-se duvidar da pertinencia dessas linhas investigativas; só não se pode esperar respondê-las com uma leitura geográfica que ignore as tramas da significação.

Essa Geografia Cultural-Humanística torna-se (e nos torna) capaz de operar a percepção de que os mais fixos dos fixos são apenas inteligíveis pelos seus movimentos. O que permitiria compor um conceito de lar em trânsito, o estudo geográfico de fenômenos, cuja força estética ou a força ética, jamais iriam requer o conceito de lar em suas escala explicativas. Neste sentido, a Terra como um lar em trânsito para movimento tem bases na Terra, 
modificando-a à razão de sua necessidades econômicas, mas também, tanto quanto, culturais, políticas e, poderíamos dizer, emocionais ou mesmo sentimentais. Fato este ligado aos princípios da Geografia Humanística, da Nova Geografia Cultural e/ou das Abordagens Humana e Cultural em Geografia. Usamos o termo Geografia Cultural-Humanística motivados por essa discussão.

O cuidado com a escala é algo de suma importância. Buttimer (1985) já chamava atenção para isso. Diante da complexidade, não dada mas compreendida, nós geógrafos temos de ter uma consciência transescalar, por conseguinte multidimensional. A escala do ser/ estar tende a converter-se naquela que apresenta maior heterogeneidade. Deste modo, maior diversidade de elementos imaginágeis; elementos objetivos e subjetivos em interação. Alimentando o campo paradoxal das possibilidades de criar e conservar realidade que o filósofo Bartolomé Ruiz (2003) chama de semfundo humano. Toda uma representação de mobilidades passíveis de serem relacionadas em escalas de maior ou menor abrangência. Depende do olhar/fazer do geógrafo (seja ele gestor, pesquisador ou professor).

No interior e no entorno da ciência geográfica, discussões tem sido realizadas em prol de uma prática epistemológica que faça o científico dialogar como o não científico. Fóruns de discussão sobre o papel do ser humano na Terra também são idealizados, nos mais diferentes eventos que se multiplicam com a fartura das oportunidades reais e virtuais. Para bem (ou nem tanto) a Sociedade do Espetáculo de Guy Debord redesenhou o modelo de fundamentação e expansão do conhecimento científico; e pelos mais diversos mecanismos midiáticos, compôs a necessidade de discussão em tempo real de todas as escolas geográficas dentro de um mesmo mega evento. E graças a essa composição, as mesmas escolas podem se "popularizar" diante de públicos não acadêmicos.

Como ceder tal perspectiva consciente para grande parte da população? Se a Geografia Cultural-Humanística tem como papel a interpretação dessa mesma consciência, como afirmava Tuan (1985), eis uma pergunta para ser debatida nos mais diversos meios. É uma interrogação que se respondida traria a nós um tipo de reificação positiva, pois valorizaria-se a vida na Terra de forma ética, em detrimento da vida supérflua dinamizada pelo ideário consumista e, portanto, insconciente e apartado espacialmente que permeia as mentes e atitudes humanas.

Tomamos as palavras finais do capítulo 5 de Jean-Marc Besse, em seu livro Ver a Terra: Seis Ensaios sobre a Paisagem e a Geografia, para finaliarmos nossa reflexão:

A ética é uma maneira de tornar o mundo habitável. A geografia fenomenológica, segundo Dardel, que se coloca na perspectiva desta "habitabilidade" do mundo, contribui para esta destinação ética do agir humano sobre a Terra. (BESSE, 2006, p. 95)

Eis a reificação positiva. Reifica-se assim, a vida do/no planeta Terra.

\section{Notas}

${ }^{1}$ A Professora Dirce Maria Antunes Suertegaray em fala proferida na Conferência de encerramento do VI Congresso Brasileiros de Geógrafos usa o termo geografar na perspcectiva da mudança social, da tranformação de um mundo onde o cidadão é um mero consumidor, para um mundo, onde o processo de construção da cidadania seja condição de um geografar coletivo. Geografar, portanto, não é só uma tarefa de geógrafos, é uma tarefa ampla que necessita ser espraiada no corpo social.

${ }^{2}$ A Geometria opera sobre um espaço abstrato, vazio de todo conteúdo disponível para todas as 
combinações. O espaço geográfico tem um horizonte, um modelado, de cor, de densidade.
Ele é sólido, liquido ou aéreo, largo ou estreito: ele limita e ele resiste.

\section{Bibliografia}

BESSE, J ean-Marc. Ver a terra: seis ensaios sobre a paisagem e a geografia. São Paulo: Perspectiva, 2006.

BUTTIMER, Anne. Apreendendo o dinamismo do mundo vivido In: CHRISTOFOLETTI, Antônio (org). Perspectivas da Geografia. São Paulo: DIFEL, 1985, p. 165-193.

CASTRO, Iná Elias. O problema da escala. In: CASTRO, I ná E. et al (orgs). Geografia: Conceitos e Temas. 7ạ ed. Rio de Janeiro: Bertrand Brasil, 2005, p. 117-140.

CLAVAL, Paul. "A volta do cultural" na geografia. In: revista Mercator. Revista de Geografia da UFC. Ano 1, $n^{\circ} 1,2002$, p. 53-59.

A contribuição francesa ao desenvolvimento da abordagem cultural na geografia. In: ROSENDAHL, Zeny, CORREAA, Roberto L. (orgs). I ntrodução à Geografia Cultural. Rio de Janeiro: Bertrand Brasil, 2003, p. 147-166.

CORRÊA, Roberto Lobato. Espaço, um conceitochave da geografia. In: CASTRO, Iná E. et al (orgs). Geografia: Conceitos e Temas. $7^{\mathrm{a}}$ ed. Rio de Janeiro: Bertrand Brasil, 2005. p. 15-47.

DARDEL, Eric: L'Homme et la Terre: nature de la réalité géographique. Paris: CTHS, 1990.

HISSA, Cássio E. Viana. A mobilidade das fronteiras: inserções da geografia na crise da modernidade. Belo Horizonte: Editora UFMG, 2002.

HOLZER, Werther. de. A geografia fenomenológica de Eric Dardel. In: ROSENDAHL, Zeny, CORREAA, Roberto L. (orgs). Matrizes da Geografia Cultural. Rio de J aneiro: EdUERJ , 2001, p. 103-122.
LOWENTHAL, David. Geografia, experiência e imaginação: em direção a uma epistemologia geográfica. In: CHRISTOFOLETTI, Antônio (org). Perspectivas da Geografia. São Paulo: DIFEL, 1985, p. 103-141.

MARANDOLA JR., Eduardo. Humanismo e abordagem cultural em geografia. In: GEOGRAFIA, Rio Claro, v. 30, n. 3, set./dez. 2005, p. 393-419.

MELLO, João B. F. de. Descortinando e (re)pensando categorias espaciais com base na obra de Yi-Fu Tuan. In: ROSENDAHL, Zeny, CORRÊA, Roberto L. (orgs). Matrizes da Geografia Cultural. Rio de Janeiro: EdUERJ, 2001, p. 87101.

MOREIRA, Ruy. Pensar e ser em geografia: ensaios de história, epistemologia e ontologia do espaço geográfico. São Paulo: Contexto, 2007.

RUIZ, Castor Bartolomé. Os paradoxos do Imaginário. São Leopoldo-RS: Editora Unisinos, 2003.

SAINT-EXUPÉRY, Antoine. Terra dos homens. 1a ed. Especial. Rio de janeiro: Nova Fronteira, 2006.

SOUZA, Marcelo J osé L. de. O Território: sobre espaço e poder, autonomia e desenvolvimento. In: CASTRO, I ná E. et al (orgs). Geografia: Conceitos e Temas. 7a ed. Rio de Janeiro: Bertrand Brasil, 2005, p. 77-116.

TUAN, Yi-Fu. Geografia humanística. In: CHRISTOFOLETTI, Antônio (org). Perspectivas da Geografia. São Paulo: DIFEL, 1985, p. 143-164.

Trabalho enviado em novembro de 2008 Trabalho aceito em março de 2009 
